\title{
National Trends in Food Insecurity and Congregation-Based Food Provision between 1998 and 2012
}

\author{
Karen Florez \\ Brad R. Fulton \\ Kathryn Derose
}

\begin{abstract}
Food insecurity has been a persistent problem in the U.S., and yet over the past three decades, federally funded food programs have become more restrictive. Scholars and policymakers have inquired whether the nonprofit sector is increasing its food provision activities to address this unmet need. This study analyzes data from the U.S. Census and a nationally representative survey of religious congregations in the U.S. to examine trends in food insecurity and congregation-based food provision between 1998 and 2012. The objective of the study is to investigate the extent to which congregation-based food provision fluctuated with national food insecurity prevalence for the overall population, and for subgroups vulnerable to this condition. Results show an over-time correspondence between the prevalence of foodinsecure households and the prevalence of congregations that provide food. Parallel patterns are observed between food insecurity in disproportionately affected subpopulations (e.g., AfricanAmericans and immigrants) and food provision in the congregations likely to serve those households. These findings indicate that congregations are helping meet the needs of foodinsecure households. However, research suggests that congregations and nonprofits are not an adequate substitute for federally funded programs. Policy recommendations include expanding access to federally funded programs like the Supplemental Nutrition Assistance Program (SNAP) to more immigrants and other groups vulnerable to food insecurity, as well as providing more systematic financial or federal support and quality control of congregation-based efforts.
\end{abstract}




\section{National Trends in Food Insecurity and Congregation-Based Food Provision between 1998 and 2012}

\section{Introduction}

Food insecurity_lacking consistent access to enough food to support an active, healthy life — is associated with poverty and several negative outcomes related to health, education attainment, and social mobility (Gundersen, Kreider, and Pepper 2011, Alaimo, Olson, and Frongillo 2001;2002, Carmichael et al. 2007, Heflin, Siefert, and Williams 2005, Lee and Frongillo 2001, Seligman et al. 2007, Bradley et al. 2018). The U.S. Department of Agriculture (USDA) has been tracking the prevalence of food insecurity among U.S. households since 1995. Between 1995 and 2007, the percentage of food-insecure households hovered between 10\% and 12\%. Following the Great Recession (December 2007 to June 2009) (The National Bureau of Economic Research 2010), the prevalence of household food insecurity increased to over $14 \%$ and remains above pre-Great Recession levels (U.S. Department of Agriculture 2016, Wolf and Morrissey 2017).

Household food insecurity disproportionately affects certain subgroups. For example, African-American households are more than twice as likely to be food-insecure as white households (Coleman-Jensen et al. 2016a, Feeding America 2015). Specifically, between 1998 and 2012, the percentage of African-American households experiencing food insecurity remained over $20 \%$ and was consistently double the national average (Coleman-Jensen, Nord, and Singh 2013, Nord, Andrews, and Carlson 2007, Cohen, Parry, and Yang 2002). Other groups such as immigrants, very-low-income households, and those in urban areas have also consistently experienced rates of food insecurity above the national average (Coleman-Jensen et 
al. 2016a, Borjas 2004, Capps et al. 2009, Anderson et al. 2014, Hadley, Patil, and Nahayo 2010).

Several federally funded programs are designed to address food insecurity by providing benefits to food-insecure households. However, not everyone experiencing food insecurity is eligible for these programs, and some that are eligible do not access them (Gray Farson, Fisher, and Lauffer 2016, Alaimo, Olson, and Frongillo 2002). For example, while the Supplemental Nutrition Assistance Program (SNAP, formerly the Food Stamp Program) reduces household food insecurity (Cook and Frank 2008, Gundersen, Kreider, and Pepper 2011), the Personal Responsibility and Work Opportunity Reconciliation Act of 1996 (PRWORA) restricted eligibility criteria for SNAP by lowering the income threshold and excluding certain groups. Immigrants, in particular, initially faced some of the most stringent eligibility requirements. Undocumented immigrants are not eligible for SNAP, and even immigrants who entered the U.S. legally after 1996 were banned for their first five years of living in the U.S. from receiving federally funded benefits like SNAP (Fortuny and Chaudry 2012). Additionally, because states could avoid adhering to federal eligibility requirements by fully funding their own programs, state-level variation added another layer to an already complex system of benefit administration (Fortuny and Chaudry 2012). Accordingly, lack of information about eligibility is among the top reasons for household nonparticipation in SNAP (United States Department of Agriculture 2012). One study found that $69 \%$ of eligible nonparticipants would apply for SNAP benefits if they understood that they were eligible (Bartlett and Burnstein 2004).

Other federally funded programs, such as the Temporary Emergency Food Assistance Program, address food insecurity indirectly by providing emergency food and nutrition assistance to individual states. These programs distribute food through regional food banks and 
local agencies, which are then distributed to emergency food providers such as soup kitchens, food pantries, and shelters (Mabli et al. 2010, Daponte and Bade 2006). Research indicates that food-insecure households are becoming more reliant on these types of food providers (Berner and O'Brien 2004). Although data on emergency food providers are limited, two studies found that the majority of such providers are faith-based agencies affiliated with congregations and other religious organizations (Weinfield et al. 2014, Mabli et al. 2010). Others have found food pantries are a common service provided by congregations (Cnaan and Boddie 2001)(Fulton 2016a). Congregations may be particularly engaged in providing food, because many religious traditions have a long history of engaging in this type of service (Ley 2008, Wineburg 1992, Chavez and Williams 2001, Fulton 2016b). Congregation-based food provision programs may also be less strict with eligibility criteria than governmental programs, since clients are often not required to provide information on income or citizenship status to receive assistance (Daponte and Bade 2006). This lack of eligibility requirements potentially makes their services more accessible to a larger number of households experiencing food insecurity (Eisinger 2002, Feeding America 2010), and there is evidence that congregations serve as alternative social services providers (Cnaan, Sinha, and McGrew 2004). However, there is a dearth of research that provides quantitative evidence of the extent to which congregations may be alleviating food insecurity through congregation-based food provision programs.

In light of the persistence of food insecurity in the U.S. and the federal government's reduced involvement with alleviating food insecurity directly since 1996 , the objective of this study is to examine congregations' participation in providing food assistance. Three waves of data from a nationally representative, cross-sectional survey of religious congregations were used, which measured congregations' involvement in food provision programs between 1998 and 2012. It is 
expected that the percentage of congregations providing food fluctuates with the percentage of food-insecure households in the U.S. The reason for expecting such a correspondence is because, as noted above, not all needy households are eligible for or participate in federally-funded food assistance programs (e.g., SNAP), and congregations' emergency food provision efforts may be sensitive to these unmet needs. Furthermore, the over-time correspondence is expected to hold among subsets of congregations serving immigrant, African-American, urban, and low-income communities, which are known to have higher rates of food insecurity and/or limited eligibility for federal food assistance programs. To our knowledge, this is the first published study to test these expectations by analyzing a nationally representative sample of congregations over a period of three decades.

\section{Methods}

To examine trends in congregation-based food provision programs, this study analyzes three waves of secondary data from the National Congregations Study (NCS) (Chaves, Anderson, and Eagle 2014). The NCS is a nationally representative, repeated cross-sectional survey of religious congregations in the United States. The NCS surveyed the leader of each congregation in the sample to gather extensive data on the congregations' composition, practices, and programs. The surveys were completed via structured interviews-either in person or over the phone. The NCS's three waves of data collection occurred in 1998 ( $n=1,234$ congregations), 2006-2007 ( $n=1,506$ congregations), and 2012 ( $n=1,331$ congregations). The response rate across the three waves ranges from $73 \%$ to $80 \%$. See Chaves (2017) for a detailed description of the NCS data and methods.

The analysis uses the following NCS survey item to assess congregations' participation in food provision programs. During the structured interview, each congregational leader was asked 
to indicate whether his or her congregation had participated in or supported social service projects of any sort within the past 12 months. ${ }^{i}$ If the leader indicated that their congregation provides social service programs, the interviewer asked the leaders to describe each program in an open-ended manner. ${ }^{\text {ii }}$ For each program the leader mentioned, the interviewer probed for its purpose and recorded the verbatim descriptions provided by the leader. These verbatim descriptions were coded into a set of non-mutually-exclusive binary variables, each one indicating a specific type of service area or focus. These variables indicate congregational participation in a wide variety of social service arenas, including clothing, health, housing, education, immigration, and food provision. Two coders independently coded each verbatim response, with disagreements resolved by a referee. All of these variables are included in the NCS's publicly available dataset. This study focuses on the variable indicating whether the congregation participates in a food provision program.

In addition to assessing participation trends among the entire population of U.S. congregations, this study examines trends among subpopulations of congregations based on their ethnoracial composition, community context, and whether they specifically serve immigrants. The categories for the ethnoracial composition of a congregation are based on whether at least $80 \%$ of its regular participants are of the same race or ethnicity (e.g., predominantly AfricanAmerican). To identify characteristics of the community context in which a congregation is located, the analysis uses the following three NCS variables derived from U.S. Census data, which indicate whether: 1) at least $30 \%$ of the people in the congregation's census tract have incomes below the Federal Poverty Level; 2) at least $80 \%$ of the people in the congregation's census tract are African-American; and 3) the congregation's census tract is predominantly urban, suburban, or rural. The analysis codes a congregation as serving immigrants if, in 
response to the social service item described above, the congregation mentioned providing aid to immigrants as one of its service areas.

To assess whether changes in the percentage of congregations participating in food provision correspond to changes in the percentage of food-insecure households in the U.S., this study analyzes data from the Current Population Survey's Food Security Supplement (CPS-FSS) conducted in 1998, 2006, and 2012 (U.S. Census Bureau 2016). The CPS-FSS surveys approximately 50,000 households each year and is representative of the civilian, noninstitutionalized population in the U.S. The CPS-FSS measures food security using responses to a series of questions about conditions and behaviors that characterize households when they are having difficulty meeting basic food needs (Coleman-Jensen et al. 2016b). The questions ask how often the condition or behavior occurred during the previous 12 months due to inadequate resources for food provision. The USDA uses the responses to these questions to classify the food security status of each interviewed household. Households are coded as "food secure" if they report less than three affirmative responses and "food insecure" if they report three or more affirmative responses (Coleman-Jensen et al. 2016b). The CPS-FSS also includes information on household characteristics, which enables analyses to examine food insecurity based on ethnoracial composition, income, and immigrant status. ${ }^{\text {iii }}$ Table 1 displays the distribution of food insecure households in the U.S. in 1998, 2006, and 2012 by race/ethnicity, community context, and country of origin.

[Table 1 Here]

The analyses examine whether there is an over-time correspondence between the prevalence of food-insecure households in the U.S. and the prevalence of food-providing congregations. The first analysis uses the CPS-FSS data to plot the percentage of food-insecure 
households in the U.S. in 1998, 2006, and 2012 and uses the NCS data to plot the percentage of congregations participating in food provision programs during those same years. An over-time correspondence is assessed by comparing the trend lines for food-insecurity levels and congregation-based food provision programs between 1998 and 2012. Subsequent analyses generate similar graphs for subpopulations of U.S. households that tend to have higher rates of food insecurity and the corresponding subpopulations of U.S. congregations that are likely to serve those households. All of the analyses in this study use the NCS congregation-level weights. ${ }^{\text {iv }}$

\section{Results}

The graph in Figure 1 plots the percentage of food-insecure households in the U.S. in 1998, 2006, and 2012 and the percentage of congregations in the U.S. participating in food provision programs during those same years. The graph shows an over-time correspondence between the prevalence of food-insecure households and the prevalence of food providing congregations. The percentage of food-insecure households decreased from $11.8 \%$ to $10.9 \%$ between 1998 and 2006 and then increased to $14.5 \%$ in 2012. During this same time period, a parallel pattern is observed for the percentage of congregations involved in providing food. Between 1998 and 2006, the percentage of congregations participating in food provision programs decreased from $33.3 \%$ to $24.5 \%$ and then increased to $40.3 \%$ in 2012 .

[Figure 1 Here]

Similar patterns are observed among subpopulations of U.S. households that tend to have higher rates of food insecurity and the corresponding subpopulations of U.S. congregations that are likely to serve those households. The graph in Figure 2 plots the percentage of food-insecure African-American households in 1998, 2006, and 2012 and the percentage of predominantly 
African-American congregations participating in food provision programs during those same years. The percentage of food-insecure African-American households decreased from $24.3 \%$ to $21.8 \%$ between 1998 and 2006 and then increased to $24.6 \%$ in 2012. During this same time period, the percentage of predominantly African-American congregations participating in food provision programs decreased from $22.8 \%$ to $16.7 \%$ between 1998 and 2006 and then increased to $41.2 \%$ in 2012 . A similar pattern is observed among congregations located in predominantly African-American neighborhoods. The graph in Figure 3 indicates that the percentage of congregations in predominantly African-American neighborhoods participating in food provision programs decreased from $24.6 \%$ to $21.7 \%$ between 1998 and 2006 and then increased to $27.1 \%$ in 2012 .

[Figures 2 and Figure 3 Here]

Figure 4 displays the parallel trend for households and congregations in urban areas. The percentage of food-insecure households in urban areas decreased from $16.4 \%$ to $13.2 \%$ between 1998 and 2006 and then increased to $16.9 \%$ in 2012. During this same time period, the percentage of congregations in urban areas participating in food provision programs decreased from $37.1 \%$ to $28.8 \%$ between 1998 and 2006 and then increased to $42.8 \%$ in 2012 .

[Figure 4 Here]

The graph in Figure 5 plots the percentage of very-low-income households (i.e., households with incomes below the Federal Poverty Level) that are food insecure and the percentage of congregations in poor neighborhoods participating in food provision programs. The percentage of very-low-income households that are food insecure decreased from $38.1 \%$ to $36.3 \%$ between 1998 and 2006 and then increased to $40.9 \%$ in 2012. During this same time period, the percentage of congregations in poor neighborhoods participating in food provision 
programs decreased from $21.7 \%$ to $17.7 \%$ between 1998 and 2006 and then increased to $45.6 \%$ in 2012.

[Figure 5 Here]

Figure 6 displays the parallel trend for immigrant households (i.e. not U.S. born) and congregations that serve immigrants. The percentage of immigrant households that are food insecure decreased from $16.8 \%$ to $13.4 \%$ between 1998 and 2006 and then increased to $17.4 \%$ in 2012. During this same time period, the percentage of immigrant-serving congregations participating in food provision programs decreased from $71.7 \%$ to $52.3 \%$ between 1998 and 2006 and then increased to $80.3 \%$ in 2012. Comparing this graph to the graphs in the previous figures indicates that immigrant households have higher levels of food insecurity compared to the national average and congregations that serve immigrants are among the most likely to participate in food provision programs.

[Figure 6 Here]

In summary, the analysis indicates an over-time correspondence between the prevalence of food-insecure households and the prevalence of food providing congregations in 1998, 2006, and 2012. The analysis also indicates parallel patterns between food insecurity in subpopulations of U.S. households that tend to have higher rates of food insecurity and food provision programs in the congregations that are likely to serve those households. Meanwhile, the government's relative involvement in food provision has been declining and the percentage of food-insecure households receiving assistance from programs like SNAP has been decreasing (Anderson 2013, Berner and O'Brien 2004, Oliveira 2017).

\section{Discussion}


To our knowledge, this is the first study to compare national trends in the prevalence of food insecurity with congregation-based food provision programs in the U.S. This study finds that across the data collection points of 1998, 2006, and 2012, trends in the percentage of congregations participating in food provision programs corresponded with trends in the percentage of food-insecure households in the U.S. Specifically, as the percentage of foodinsecure households decreased between 1998 and 2006, the percentage of congregations providing food also decreased. Then, between 2006 and 2012, as the percentage of food-insecure households increased, the percentage of congregations providing food also increased. These findings provide evidence that congregations' involvement in food provision is sensitive to the food needs of their surrounding communities. This is important knowledge, as congregationbased food provision programs could partly supplement inadequate direct programming like SNAP. However, congregations' food programs are largely dependent on private donations and food that comes from regional food banks, the latter of which rely partly on federally funded programs such as the Temporary Emergency Food Assistance Program (Chaves and Eagle 2016). Thus, congregations' ability to meet the food insecurity needs of their communities may be constrained by these other factors.

This study also examines the rates of involvement in food provision among congregations that serve subpopulations known to have high rates of food insecurity. For example, we find that predominantly African-American congregations and congregations in predominantly AfricanAmerican neighborhoods are consistently among the types of congregations with the highest rates of involvement in food provision. Furthermore, the percentage of predominantly AfricanAmerican congregations involved in food provision more than doubled between 2006 and 2012. Yet, a similar drastic increase was not observed among congregations in predominantly African- 
American neighborhoods. This difference raises a question as to who is being served by the food programs of African-American congregations. Due to demographic shifts affecting many urban areas, the racial/ethnic composition of urban congregations do not always match those of their neighborhoods (Kinney and Combs 2016, McRoberts 2003). For example, over the past several decades, the population in South Los Angeles has shifted from majority African-American to majority (mostly immigrant) Latino, yet even as African-American congregants move out of the neighborhood, their churches often remain in the neighborhood and become commuter churches that provide services (e.g., food pantries) to non-congregant community residents (Martinez 2016). Nationally, the past two decades have seen an unprecedented geographic dispersion of the U.S. Latino population, away from traditional destinations to new destinations, particularly in the Upper Midwest and the South (Gresenz et al. 2012, Frey 2005). Future research could examine the extent to which predominantly African-American congregations' food provision programs are serving Latinos (particularly immigrants) and other groups.

Regarding urban areas, there is a correspondence between the percentage of foodinsecure households in urban areas and the percentage of urban congregations providing food. Given the high rates of food insecurity among households in urban areas, future research could investigate how urban congregations are addressing food insecurity needs and whether they are adopting innovative practices such as creating urban community gardens.

Given that food insecurity is a poverty-related condition, it is not surprising that congregations in poor neighborhoods participate in food provision programs. More remarkable is that congregation-based food provision in poor neighborhoods doubled between 2006 and 2012. This sharp increase may be a response to the degree of food insecurity experienced in such communities. Studies have found a growing reliance on emergency food providers among very- 
low-income households, even among those that receive SNAP benefits (Weinfield et al. 2014, Berner and O'Brien 2004, Chhabra, Falciglia, and Lee 2014). Data indicate that very-low-income households obtain food from such providers on a regular basis rather than only during times of acute need (Weinfield et al. 2014). Consequently, more research is needed to understand the dynamics affecting food provision in poor neighborhoods and the ways very-low-income households use congregation-based food programs.

Lastly, immigrant households have higher food insecurity compared to the national average, and we find that immigrant-serving congregations are among the most likely to be involved in providing food. In 2012, over $80 \%$ of such congregations had a food provision program. We interpret this finding in the context of the policy changes that substantially restricted immigrants' access to federally sponsored food-related benefits (e.g., SNAP) beginning with PRWORA in 1996. Indeed, studies indicate a decrease in SNAP enrollment among immigrants after 1996 (National Academies of Sciences 2016), and despite efforts to restore eligibility among certain groups of immigrants (e.g., those under 18 who lived in the U.S. prior to PRWORA), participation rates among food-insecure immigrant households remain substantially lower than the national average (Eslami 2014, Potochnick 2016). There is also evidence that immigrant-serving congregations may be particularly focused on social service provision, in an attempt to ameliorate harsh social conditions (Cnaan and Curtis 2013).

As the requirements to be eligible for federal food assistance have become stricter, many food-insecure households have had to rely on alternative sources of food (Schenck-Fontaine, Gassman-Pines, and Hill 2017), and our findings suggest congregations may be a plausible venue given their trends in efforts. However, congregation-based food provision programs tend to be less reliable than federal food assistance programs since most congregations depend on 
donations and the quantity and quality of food they have available can vary substantially (Berner and O'Brien 2004, Daponte and Bade 2006). A systematic review of studies analyzing food pantry users found low dietary quality, such as lower-than-recommended consumption of fruits, vegetables, dairy, and calcium (Simmet et al. 2016). Future research could assess dietary quality among people who obtain food from congregations since congregations make up a large percentage of emergency food providers, and because congregations can serve as possible intervention sites for the promotion of healthy eating, especially among people experiencing food insecurity.

This study has some limitations that should be noted. First, although PRWORA reduced the number of people who qualified for food benefits, the NCS does not have data prior to 1996. Thus, this study is unable to assess whether PRWORA led to a greater percentage of congregations participating in food provision programs. Second, given the lack of client-level data in our congregation dataset, this study cannot provide insights at this level, including the degree of food insecurity experienced among those served. Third, the analysis does not include specific details about the scope and scale of congregations' food provision programs, including actual amount of food distributed by congregations engaged in this type of programming. Congregations' involvement in providing food can range from periodically providing meals to congregants who are sick to operating large-scale community food pantries. Future research could examine the effectiveness of such programs - i.e., the extent to which congregations are meeting the food needs of food-insecure households. Lastly, although it would be interesting to identify the types of congregations that stopped distributing food between 1998 and 2006, the cross-sectional data prevents analyses from differentiating between congregations that discontinued food provision and those that were never involved in food provision. The same data 
limitations also prevent analysts from knowing what types of congregations began (or resumed) food distribution between 2006 and 2012.

Addressing food insecurity is important for enabling people to live active, healthy lives and to achieve better health and socioeconomic outcomes, yet not everyone in the U.S. who is food insecure is eligible to receive federally funded food assistance, leading those in need to turn to other resources that may not be the most effective at reducing food insecurity. Furthermore, policy changes have further restricted access to these programs for certain populations, such as immigrants, that have a high risk of being food insecure. One policy recommendation is to expand access to federally funded programs to more immigrants and other groups vulnerable to food insecurity, because our research indicates that these groups are increasingly using congregation-based food provisions during times of need.

Findings from this study suggest that in response to the government's inadequate efforts to address food insecurity, a growing percentage of congregations, especially those that serve populations disproportionately affected by food insecurity, are providing food assistance. However, persistently high national food insecurity levels suggest that the increased congregational involvement is not sufficient to meet household needs. A second policy recommendation is for the government to examine ways to better meet the needs of its participants through various non-federal programs already established like congregations, food banks and pantries, etc.. Further, research could explore the nature of this food assistance, where congregations obtain their food, and who uses their services. Assessing people's use of congregation-based food provision programs is particularly timely given the relatively high levels of food insecurity coupled with the government's limited involvement and ongoing efforts to cut the budgets of federally funded food programs. 


\section{References}

Alaimo, K., C. M. Olson, and E. A. Frongillo. 2002. "Family food insufficiency, but not low family income, is positively associated with dysthymia and suicide symptoms in adolescents." J Nutr 132 (4):719-25.

Alaimo, K., C. M. Olson, and E. A. Frongillo, Jr. 2001. "Food insufficiency and American school-aged children's cognitive, academic, and psychosocial development." Pediatrics 108 (1):44-53.

Anderson, L., D. S. Hadzibegovic, J. M. Moseley, and D. W. Sellen. 2014. "Household food insecurity shows associations with food intake, social support utilization and dietary change among refugee adult caregivers resettled in the United States." Ecol Food Nutr 53 (3):312-32. doi: 10.1080/03670244.2013.831762.

Anderson, M.D. 2013. "Beyond food security to realizing food rights in the US." Journal of Rural Studies 29:113-122.

Bartfeld, Judith, and Fei Men. 2017. "Food Insecurity among Households with Children: The Role of the State Economic and Policy Context." Social Service Review 91 (4):691-732. doi: 10.1086/695328.

Bartlett, Susan, and Nancy Burnstein. 2004. Food Stamp Program Access Study: Eligible Nonparticipants. Cambridge, MA: Abt Associates.

Berner, M., and K. O'Brien. 2004. "The Shifting Pattern of Food Security Support: Food Stamp and Food Bank Usage in North Carolina." Nonprofit and Voluntary Sector Quaterly 33 (4):655-672.

Borjas, G.J. 2004. "Food insecurity and public assistance." Journal of Public Economics $88: 1421-1443$

Bradley, S., C. A. Vitous, A. Walsh-Felz, and D. Himmelgreen. 2018. "Food insecurity and healthcare decision making among mobile food pantry clients in Tampa Bay." Ecol Food Nutr 57 (3):206-222. doi: 10.1080/03670244.2018.1455673.

Capps, R., A. Horowitz, K. Fortuny, J. Bronte-Tinkew, and M. Zaslow. 2009. Young children in immigrant families face higher risk of food insecurity. Child Trends.

Carmichael, S. L., W. Yang, A. Herring, B. Abrams, and G. M. Shaw. 2007. "Maternal food insecurity is associated with increased risk of certain birth defects." J Nutr 137 (9):208792.

Chaves, Mark. 2017. "National Congregations Study." accessed 15 January 2017. www.soc.duke.edu/natcong.

Chaves, Mark, Shawna Anderson, and Alison Eagle. 2014. National Congregations Study: Cumulative Datafile and Codebook. Durham: Duke University, Department of Sociology.

Chavez, M., and T. Williams. 2001. "Congregation and social services: What they do, how they do it, and with whom." Nonprofit and Voluntary Sector Quaterly 60:660-83.

Chhabra, S., G. A. Falciglia, and S. Y. Lee. 2014. "Social capital, social support, and food insecurity in food pantry users." Ecol Food Nutr 53 (6):678-92. doi: 10.1080/03670244.2014.933737.

Cnaan, R.A., and S.C. Boddie. 2001. "Philadelphia Census of Congregations and Their Involvement in Social Service Delivery." Social Service Review 75 (4):559-580.

Cnaan, R.A., and D.W. Curtis. 2013. "Religious Congregations as Voluntary Associations: An Overview." Nonprofit and Voluntary Sector Quaterly 42 (1):7-33. 
Cnaan, Ram A., Jill W. Sinha, and Charlene C. McGrew. 2004. "Congregations as Social Service Providers." Administration in Social Work 28 (3-4):47-68. doi: 10.1300/J147v28n03 03.

Cohen, B., J. Parry, and K. Yang. 2002. Household Food Security in the United States, 1998 and 1999. edited by Economic Research Service.

Coleman-Jensen, A., M. Nord, and A. Singh. 2013. Houeshold Food Security in the United States in 2012. edited by Economic Research Service.

Coleman-Jensen, A., M.P. Rabbitt, C.A. Gregory, and A. Singh. 2016a. Household Food Security in the United States in 2015. edited by Economic Research Service: U.S. Department of Agriculture.

Coleman-Jensen, A., M.P. Rabbitt, C.A. Gregory, and A. Singh. 2016b. Statistical Supplement to Household Food Security in the United States in 2015: AP-072, U.S. Department of Agriculture, Economic Research Service.

Cook, J. T., and D. A. Frank. 2008. "Food security, poverty, and human development in the United States." Ann N Y Acad Sci 1136:193-209. doi: 10.1196/annals.1425.001.

Daponte, B.O., and S. Bade. 2006. "How the Private Food Assistance Network Evolved: Interactions between Public and Private Responses to Hunger." Nonprofit and Voluntary Sector Quaterly 35 (4):668-690.

Eisinger, P. 2002. "Organizational capacity and organizational effectiveness among street-level food assistance programs." Nonprofit and Voluntary Sector Quaterly 31:115-30.

Eslami, E. 2014. Trends in Supplemental Nutrition Assistance Program Participation Rates: Fiscal Year 2010 to Fiscal Year 2012. Mathematica Policy Research Inc.

Feeding America. 2010. edited by Hunger's New Staple: Feeding America.

Feeding America. 2015. Map the Meal Gap. Feeding America.

Fortuny, K., and A. Chaudry. 2012. Overview of immigrants' eligibility for SNAP, TANF, Medicaid and CHIP. In Immigrant Access to Health and Human Services, edited by Office of the Assistant Secretary for Planning and Evaluation. Washington, DC: US Department of Health and Human Services

Frey, W. 2005. Immigration and Domestic Migration in US Metro Areas: 2000 and 1990 Census Findings by Education and Race. Population Studies Center.

Fulton, B. 2016. "Trends in addressing social needs: A longitudinal study of congregation-based service provision and political participation." Religions 7:51-67.

Gray Farson, K., S. Fisher, and S. Lauffer. 2016. Characteristics of Supplemental Nutrition Assistance Program Households: Fiscal year 2015. edited by Food and Nutrition Service. Alexandria, VA: Office of Policy Support.

Gresenz, C. R., K. P. Derose, T. Ruder, and J. J. Escarce. 2012. "Health care experiences of Hispanics in new and traditional U.S. destinations." Med Care Res Rev 69 (6):663-78. doi: $10.1177 / 1077558712457242$.

Gundersen, K., B. Kreider, and J. Pepper. 2011. "The economics of food insecurity in the United States." Applied Economic Perspective 33 (3):281-303.

Hadley, C., C. L. Patil, and D. Nahayo. 2010. "Difficulty in the food environment and the experience of food insecurity among refugees resettled in the United States." Ecol Food Nutr 49 (5):390-407. doi: 10.1080/03670244.2010.507440.

Heflin, C. M., K. Siefert, and D. R. Williams. 2005. "Food insufficiency and women's mental health: findings from a 3-year panel of welfare recipients." Soc Sci Med 61 (9):1971-82. doi: 10.1016/j.socscimed.2005.04.014. 
Kinney, N., and T.B. Combs. 2016. "Changes in religious ecology and socioeconomic correlates for neighborhood in a metropolitan region." Journal of Urban Affairs 38:409-28.

Lee, J. S., and E. A. Frongillo, Jr. 2001. "Nutritional and health consequences are associated with food insecurity among U.S. elderly persons." J Nutr 131 (5):1503-9.

Ley, D. 2008. "The Immigrant Church as an Urban Service Hub." Urban Studies 45 (10):20572074.

Mabli, J., R. Cohen, F. Potter, and Z. Zhao. 2010. Hunger in America 2010. Mathematica Policy Inc.

Martinez, C. 2016. The Neighborhood Has Its Own Rules: Latinos and African Americans in South Los Angeles. New York: NYU Press.

McRoberts, O.M. 2003. Streets of Glory: Church and Community in a Black Urban Neighborhood. Chicago: University of Chicago.

National Academies of Sciences, Engineering, and Medicine,. 2016. The Economic and Fiscl Consequences of Immigration. Washington, DC: The National Acadmies of Press.

Nord, M., M. Andrews, and S. Carlson. 2007. Household Food Security in the United States, 2006. edited by Economic Research Service.

Oliveira, V. 2017. The Food Assistance Landscape: FY 2016 Annual Report.

Potochnick, S. 2016. "Reversing welfare reform? Immigrant restoration efforts and food stamp recepit among Mexican immigrant families." Social Science Research 60:88-89.

Schenck-Fontaine, Anika, Anna Gassman-Pines, and Zoelene Hill. 2017. "Use of Informal Safety Nets during the Supplemental Nutrition Assistance Program Benefit Cycle: How Poor Families Cope with Within-Month Economic Instability." Social Service Review 91 (3):456-487. doi: 10.1086/694091.

Seligman, H. K., A. B. Bindman, E. Vittinghoff, A. M. Kanaya, and M. B. Kushel. 2007. "Food insecurity is associated with diabetes mellitus: results from the National Health Examination and Nutrition Examination Survey (NHANES) 1999-2002." J Gen Intern Med 22 (7):1018-23. doi: 10.1007/s11606-007-0192-6.

Simmet, A., J. Depa, P. Tinnemann, and N. Stroebele-Benschop. 2016. "The Dietary Quality of Food Pantry Users: A Systematic Review of Existing Literature." J Acad Nutr Diet. doi: 10.1016/j.jand.2016.08.014.

The National Bureau of Economic Research. 2010. "U.S. Business Cycle Expansions and Contractions." accessed March 22. http://www.nber.org/cycles.html.

U.S. Census Bureau. 2016. "Current Population Survey Food Security Supplement 1998, 2006, 2012."

U.S. Department of Agriculture. 2016. "Food Security Trends in the United States." https://www.ers.usda.gov/data-products/food-security-in-the-united-states/interactivechart-food-security-trends/.

United States Department of Agriculture. 2012. Building a Healthy America: A Profile of the Supplemental Nutrition Assistance Program. edited by Office of Research and Analysis. Washington DC.

Weinfield, N.S., G. Mills, C. Borgert, M. Gearing, T. Macaluso, J. Montaquila, and S. Zedlewski. 2014. Hunger in America 2014: National Report. Feeding America.

Wineburg, R.J. 1992. "Local Human Services Provision by Religious Congregations: A Community Analysis." Nonprofit and Voluntary Sector Quaterly 21 (2):107-117. 


\section{Wolf, Sharon, and Taryn Morrissey. 2017. "Economic Instability, Food Insecurity, and Child Health in the Wake of the Great Recession." Social Service Review 91 (3):534-570. doi: $10.1086 / 694111$.}

\footnotetext{
i In Waves II and III, if the respondent answered "no" to this question, the interviewer asked follow-up questions to probe into whether the congregation provided any type of social services. For consistency, in order to assess change over time related to this item, Wave II and Wave III responses generated from the follow-up questions were not included in the analysis.

ii In Wave III, congregations that offered four or fewer programs were asked to describe each program. Congregations that offered more than four programs were asked to describe their four most important programs. Among the congregations reporting some social service activity, $27 \%$ reported more than four programs. This methodological difference between Wave III and Waves I and II means that for comparison across waves, the percentage of congregations involved in food provision programs in Wave III may be underestimated if some of the congregations that offered more than four programs did not view their food provision program as one of their four most important programs and thus did not report it. However, because the percentage of congregations participating in food provision in Wave III exceeds the percentages in Waves I and II, an underestimation of this statistic in Wave III would not affect the upward trends observed nor the conclusions drawn.

iii the Current Population Survey (CPS) classifies a household based on the attributes of the household reference person. For example, if the household reference person is African-American, the CPS classifies the household as African-American.

${ }^{\text {iv }}$ For all of the analyses in this study, the NCS data are weighted using the following congregation level weightwt_all3_cong_dup — which treats each congregation as one unit regardless of its size. This is the appropriate weight to use when assessing trends among congregations because a congregation's likelihood of appearing in the NCS sample is proportional to its size and using the congregation level weight undoes the over-representation of larger congregations in the NCS (Chaves et al. 2014).
} 
Table 1: Distribution of food insecure households in the U.S. in 1998, 2006, and 2012

\begin{tabular}{lrrr}
\hline Percentage of... & \multicolumn{1}{c}{1998} & \multicolumn{1}{c}{2006} & 2012 \\
\hline Households that are food insecure & $11.8 \%$ & $10.9 \%$ & $14.5 \%$ \\
Caucasian households that are food insecure & $8.3 \%$ & $7.8 \%$ & $11.2 \%$ \\
African-American households that are food insecure & $24.3 \%$ & $21.8 \%$ & $24.6 \%$ \\
Hispanic households that are food insecure & $25.0 \%$ & $19.5 \%$ & $23.3 \%$ \\
Households in urban areas that are food insecure & $16.4 \%$ & $13.2 \%$ & $16.9 \%$ \\
Households in suburban areas that are food insecure & $9.3 \%$ & $9.0 \%$ & $12.7 \%$ \\
Households in rural areas that are food insecure & $11.9 \%$ & $12.0 \%$ & $15.5 \%$ \\
Very low income households that are food insecure & $38.1 \%$ & $36.3 \%$ & $40.9 \%$ \\
U.S. born households that are food insecure & $11.3 \%$ & $10.6 \%$ & $14.0 \%$ \\
Immigrant households that are food insecure & $16.8 \%$ & $13.4 \%$ & $17.4 \%$ \\
\hline
\end{tabular}

Source: Current Population Survey's Food Security Supplement (U.S. Census Bureau 2016) 
Figure 1. Trends in the percentage of food insecure households in the U.S. and the percentage of congregations in the U.S. participating in food provision programs in 1998, 2006, and 2012

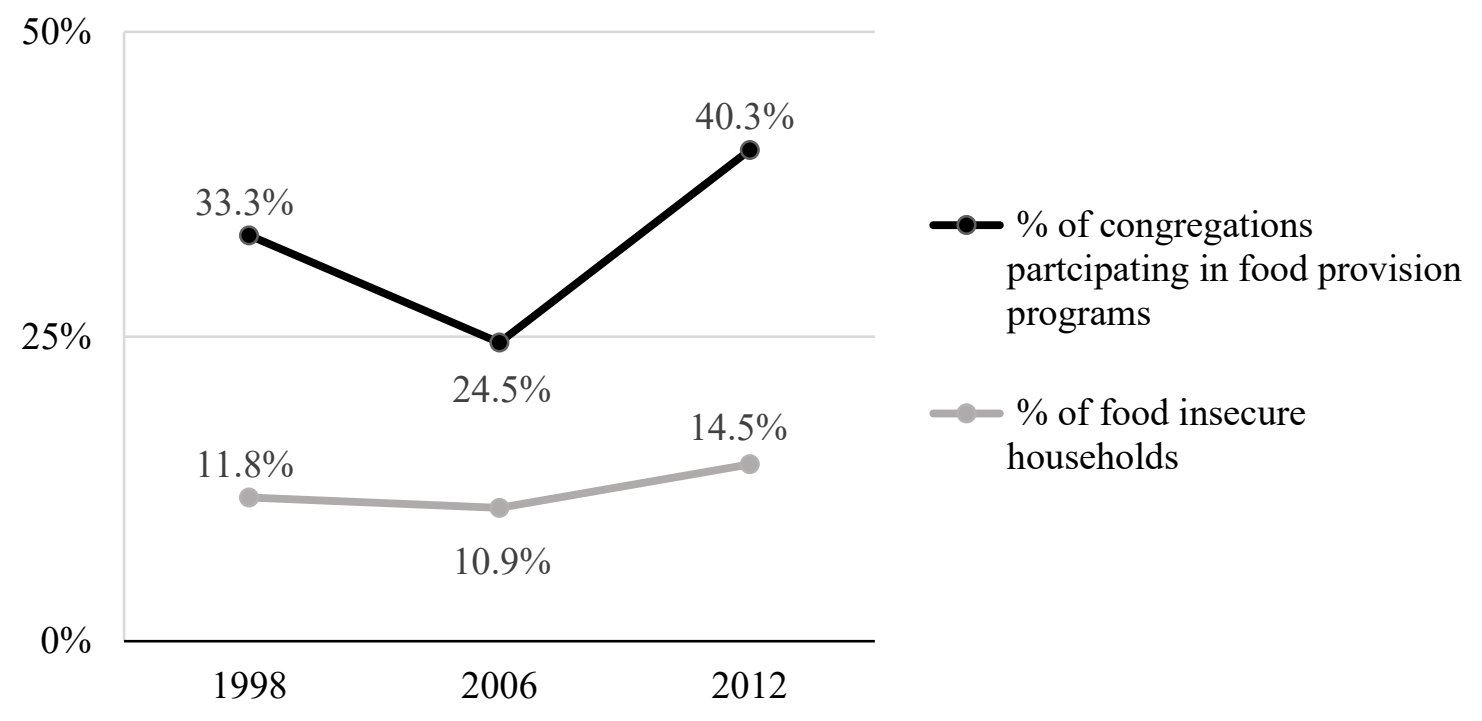


Figure 2. Trends in the percentage of African-American households that are food insecure and the percentage of predominantly African-American congregations participating in food provision programs in 1998, 2006, and 2012

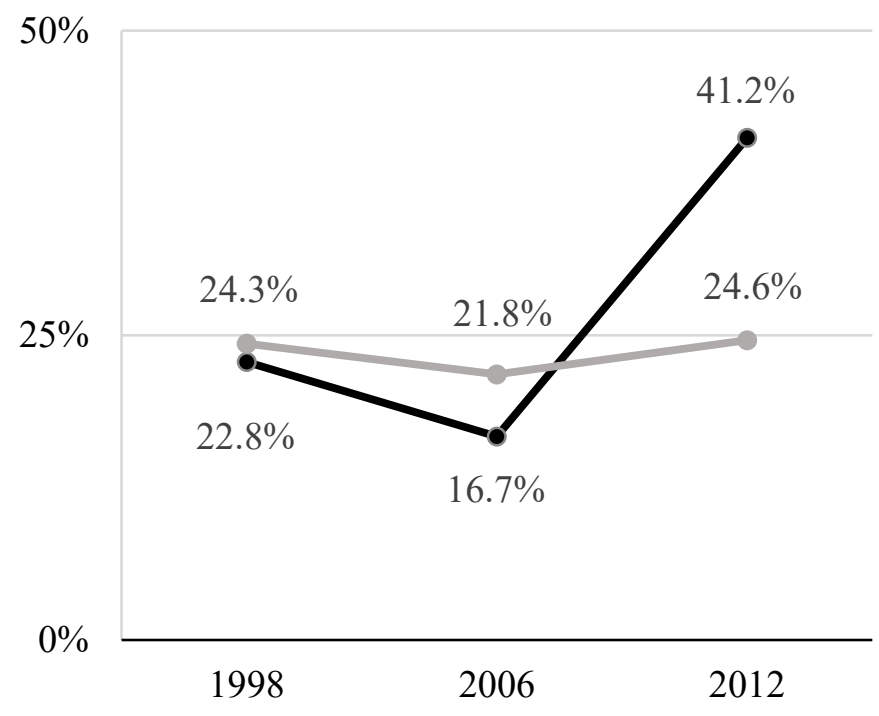

-० $\%$ of predominantly AfricanAmerican congregations participating in food provision programs

- $\%$ of African-American households that are food insecure 
Figure 3. Trends in the percentage of African-American households that are food insecure and the percentage of congregations in predominantly African-American neighborhoods participating in food provision programs in 1998, 2006, and 2012

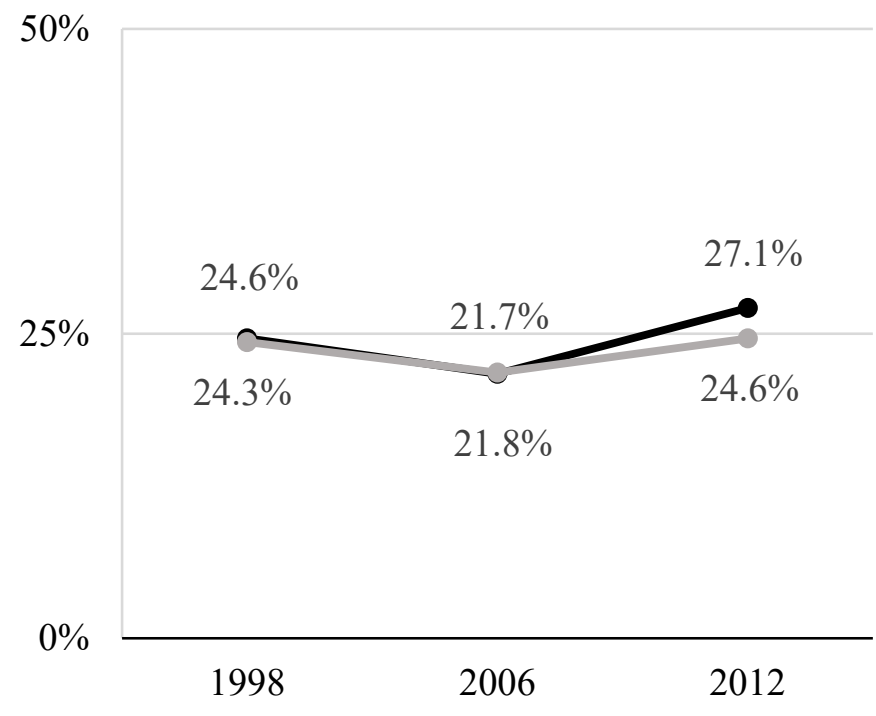

$\rightarrow \%$ of congregations in predominantly AfricanAmerican neighborhoods participating in food provision programs $-\%$ of African-American households that are food insecure 
Figure 4. Trends in the percentage of food insecure households in urban areas and the percentage of congregations in urban areas participating in food provision programs in 1998, 2006, and 2012

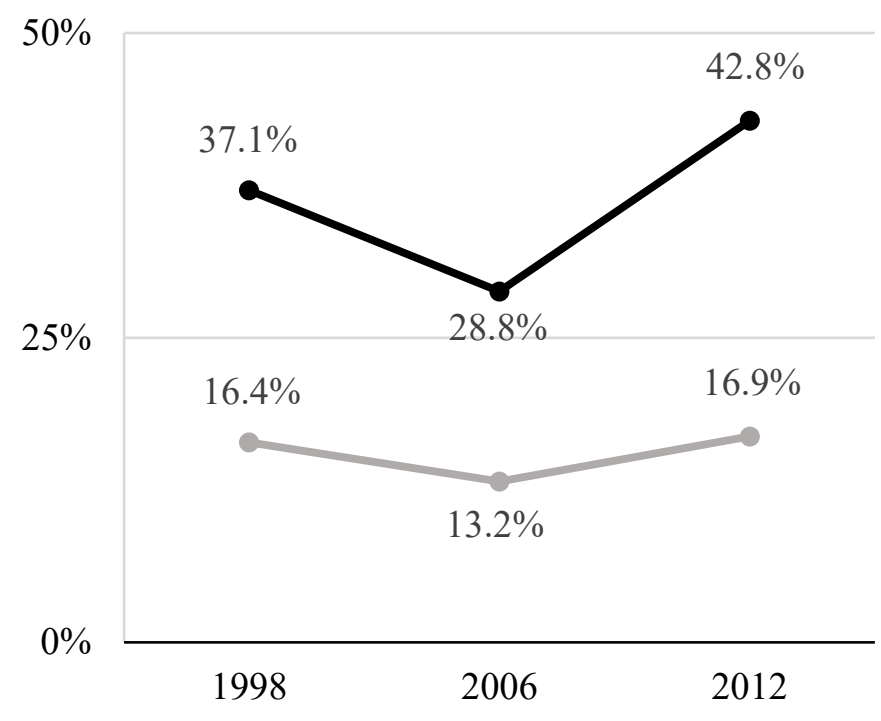

$\longrightarrow \%$ of congregations in urban areas participating in food provision programs

$-\%$ of food insecure households in urban areas 
Figure 5. Trends in the percentage of very-low-income households (i.e., households with incomes below the Federal Poverty Level) that are food insecure and the percentage of congregations in poor neighborhoods participating in food provision programs in 1998, 2006, 2012

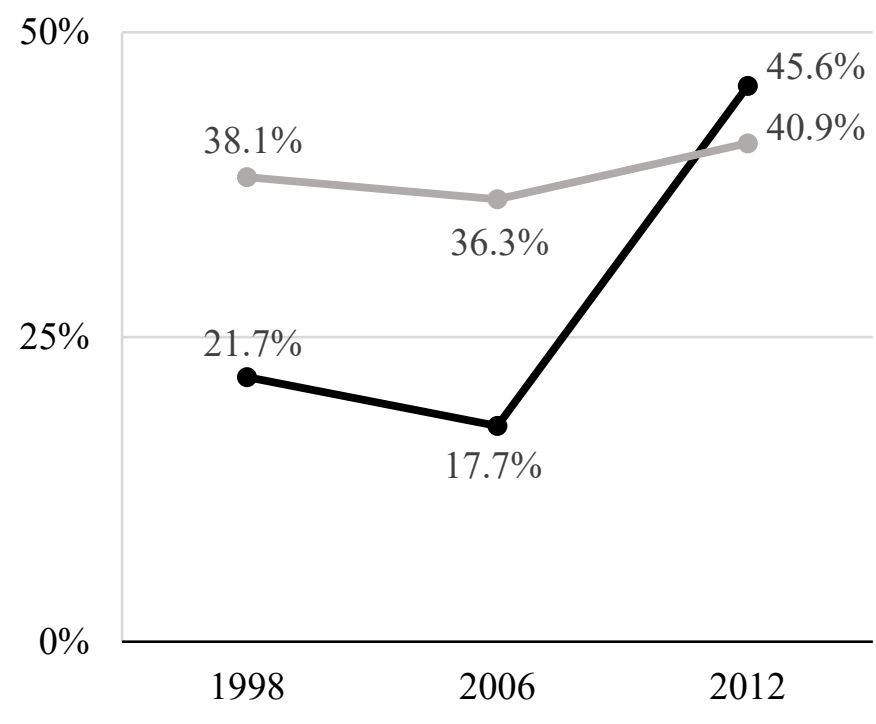

$\rightarrow \%$ of congregations in poor neighborhoods participating in food provision programs

$-\%$ of very-low-income households that are food insecure 
Figure 6. Trends in the percentage of immigrant households (i.e. not U.S. born) that are food insecure and the percentage of immigrant serving congregations participating in food provision programs in 1998, 2006, and 2012

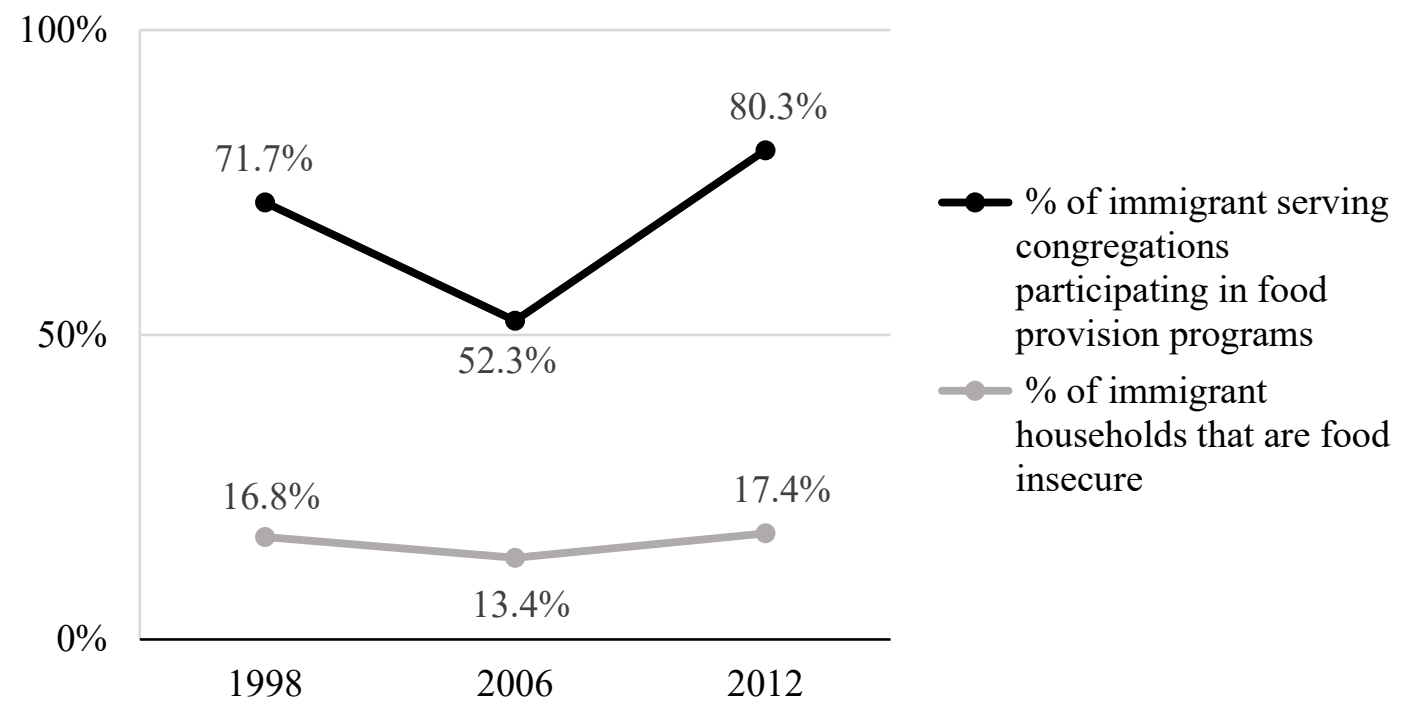

